\title{
Os Chineses no Rio: A Escravidão Urbana
}

Ricardo Rezende Figueira ${ }^{1}$,
Suliane Sudano ${ }^{2}$
\& Edna Galvão ${ }^{3}$

Este artigo destina-se a apresentar a primeira etapa de pesquisa que está sendo desenvolvida pelo Grupo de Pesquisa em Trabalho Escravo Contemporâneo - GPTEC, do Núcleo de Estudos de Políticas Públicas em Direitos Humanos, Universidade Federal do Rio de Janeiro - UFRJ.

Encontram-se atualmente no Brasil milhares de pessoas provenientes da República Popular da China. Uma parte substancial chegou ao país a partir da década de 1990 e, provavelmente, trata-se de migração provocada especialmente pela necessidade econômica, como indicam alguns estudos ${ }^{4}$. Quem chega é imigrante, tem seus estranhamentos e é estranhado, como um outsider 5 . Há indícios de que muitos dos que aqui chegam convivem com problemas graves de adaptação e estão em situação irregular.

Nosso trabalho exploratório está direcionado para o contingente de chineses que chega ao Brasil e passa a atuar em estabelecimentos comerciais da região metropolitana

\footnotetext{
${ }^{1}$ Doutor em Programa de Pós-Graduação em Sociologia e Antropologia pela Universidade Federal do Rio de Janeiro.

${ }^{2}$ Assistente Social e pesquisadora no GPTEC/NEPP da UFRJ.

${ }^{3}$ Historiadora e pesquisadora do GPTEC/NEPP da UFRJ.

${ }^{4}$ Para maiores esclarecimentos sobre o tema, ler: Cunha e Mello (2006) e Piza (2012).

${ }^{5} \mathrm{O}$ termo outsider surgiu como demanda para estruturar um caso estudado por Norbert Elias. A partir desse estudo revelou-se que o poder de estigmatização que um grupo exercia sobre outro, quando não havia diferença racial, militar, religiosa ou econômica, estava na capacidade de manter a coesão enquanto grupo. Os outsiders eram aqueles pertencentes a um grupo que não possuía uma coesão significativa. (Elias e Scotson, 2000: 21-24)
}

Brasiliana - Journal for Brazilian Studies. Vol. 2, n.2 (Nov 2013). ISSN 2245-4373. 
do Rio de Janeiro, em pastelarias, no pequeno comércio familiar, ou estão inseridos em atividades religiosas, no espaço evangélico ou católico.

Apresentaremos o caso de Yin Qiang Quan, um jovem chinês que foi libertado de uma pastelaria em abril de 2013, e pode representar apenas a ponta de um problema maior. Tomamos como hipótese a afirmativa de que, como no referido caso, há escravidão por dívida nas relações de trabalho entre migrantes chineses, no Brasil. O objetivo da pesquisa consiste em apreender a presença destes chineses no Brasil, conhecer melhor suas condições de trabalho e de vida, bem como as redes ${ }^{6}$ que envolvem submissão e exploração, e os esquemas que os mantém em relações específicas. Temos dificuldades ampliadas em função da cultura7 ${ }^{7}$ da língua e do silêncio que pode se estabelecer na circulação das informações.

A capacidade de refletir, investigar, conduzir a ação de maneira planejada, consciente e crítica é o que nos possibilita construir meios de intervir e transformar a realidade. Contudo, estamos conscientes dos limites impostos por questões estruturais que precisam ser enfrentadas, considerando as alternativas e possibilidades de mudanças presentes nesta realidade. Estamos conscientes também de que é necessária a mobilização de diversos atores sociais na busca por mudanças, cidadãos, instâncias intragovernamentais, intergovernamentais e não governamentais, movimentos sociais e

\footnotetext{
${ }^{6}$ O papel das chamadas "redes sociais" comumente é associado por parte da literatura sobre migrações a uma solidariedade étnica vinculada a benefícios mútuos. A perspectiva aqui utilizada diverge desta no sentido de que entende "os efeitos recorrentes da participação em diversas redes sociais (no plural, porque são várias) como uma mescla ambivalente de débitos e favores, prejuízos e vantagens, exploração e ajuda mútua. Entre aprisionamento ou conquistas, os resultados podem variar e parecem ser decorrentes de tramas de relações sociais situacionais, dos múltiplos possíveis vínculos em contextos específicos”. (Piza, 2012: 160)

${ }^{7}$ A cultura, como conceito antropológico, é analisada a partir de uma perspectiva simbólica. Ao desenvolver suas relações nas diversas sociedades, o homem representaria a natureza humana, inclusive nas relações coercitivas onde se encontra o conjunto de regras e normas, sistemas de interdições e obrigações estabelecidas a partir da atribuição de valores. Além da criação da ordem simbólica da lei há um conjunto de práticas, ações, comportamento e instituições com os quais os homens se relacionam com a natureza e com outros homens na sua produção material. Consideramos que os dois conceitos são fundamentais e se complementam no sentido de trazer um esclarecimento sobre a temporalidade e a historicidade das sociedades, o que as permite passar por transformações culturais amplas (Chauí, 2000: 374-376).
}

Brasiliana - Journal for Brazilian Studies. Vol. 2, n.2 (Nov 2013). ISSN 2245-4373. 
outros. Por fim, a pesquisa tem como finalidade contribuir por meio da divulgação da temática, bem como através da participação na elaboração de políticas públicas como parte de estratégias de superação.

Para isso, entendemos ser necessário no decorrer da pesquisa: maior conhecimento sobre a cultura chinesa para uma possível aproximação com os migrantes; ampliação de informações necessárias à observação etnográfica; contextualização a partir de estudo da história e da geopolítica chinesa, o que nos permitirá maior entendimento sobre as atuais migrações.

A metodologia caracteriza-se por pesquisa bibliográfica, leitura de teses, dissertações e artigos de autores que se dedicam à temática desse tipo de migração, do universo cultural chinês e de questões referentes à contextualização histórica da China e do Brasil na atualidade; visitas a associações, a órgãos públicos e instituições culturais chinesas; observação direta; entrevistas estruturadas e semiestruturadas, com roteiro de pesquisa, instrumento utilizado na orientação e no auxílio à reconstituição de histórias de vida; estudos de caso.

Algumas entrevistas estão sendo realizadas com migrantes de Guangdong em Igrejas evangélicas, após os cultos que acontecem aos domingos. Entrevistamos um historiador chinês que pesquisa a temática da China em seu aspecto econômico e cultural. No sentido de compreender a dinâmica das relações comerciais entre os migrantes chineses e libaneses, o presidente da Sociedade de Amigos das Adjacências da Rua da Alfândega - SAARA, também foi entrevistado.

A pesquisa conta com a parceria informal de profissionais do Ministério Público do Trabalho e do Ministério do Trabalho e Emprego. Contribui também, nesta pesquisa, um casal que viveu na China por aproximadamente quinze anos e fala o idioma mandarim, além de outra participante bastante interessada na temática. Tais pessoas 
vinculadas à Igreja evangélica propuseram-se a colaborar e fornecem informações e contatos, de forma voluntária.

Para entendermos as relações que marcam a migração chinesa na atualidade, é essencial a aproximação com a cultura chinesa, as formas de trabalho, a atuação em redes, a organização dos chineses no que tange às transações financeiras, seus valores, como concebem as relações familiares e comerciais.

Alguns referenciais teóricos auxiliam na compreensão de aspectos da migração chinesa no Brasil, nesta fase da pesquisa, tais como: Rosana Pinheiro-Machado, Neiva Vieira da Cunha e Pedro Paulo Thiago de Mello contribuem na discussão sobre o processo migratório; Douglas de Toledo Piza problematiza a questão da "rede" como categoria de análise; Norbert Elias e John Scotson norteiam o conceito de "alteridade" nesse processo investigativo. Para efeito de analisar comparativamente as relações econômicas entre o oriente e o ocidente, Claude Meillassoux contribui na medida em que apresenta estudo da sociedade escravista na África pré-colonial e colonial, e Leonardo Sakamoto, com análises econômicas do Brasil nos séculos XX e XXI. Outros autores também deverão ser consultados no decorrer da pesquisa.

\section{A Conjuntura Brasil-China no Contexto da Atualidade}

A abertura dos mercados, os fluxos financeiros, as mudanças nas políticas de migração e de comércio, a mobilização das unidades de produção, são questões que ao serem estudadas, poderão auxiliar no entendimento de aspectos relacionados às recentes migrações chinesas. As reformas políticas e aberturas comerciais da era Deng Xiaoping8

\footnotetext{
${ }^{8}$ Político e líder comunista chinês nascido na província de Sichuan, principal inspirador da reação contra o maoísmo e da introdução das últimas grandes reformas políticas e econômicas na China (1980-1990). Disponível em: <http://www.dec.ufcg.edu.br/biografias/> Acesso em 10 set 2013.
}

Brasiliana - Journal for Brazilian Studies. Vol. 2, n.2 (Nov 2013). ISSN 2245-4373. 
até os dias atuais possibilitaram uma flexibilização das migrações internas e internacionais.

A maior parte dos migrantes chineses que chega ao Brasil é proveniente da região de Guangdong, província onde estão concentradas as principais Zonas Econômicas Especiais - ZEE, como Shenzhen, Zhuhai e Shantou. As ZEE foram criadas em 1979 e tornaram-se zonas especiais de exportação. Em 1984, 14 cidades de zonas costeiras integraram-se às ZEE passando a ter vantagens econômicas, tais como carga tributária mais baixa e condições autônomas políticas e mercantis. Além de ser a província de Guangdong a mais urbanizada da China, anunciavam em 2009 os gabinetes oficiais que seu emblema econômico acusava o maior PIB da República Popular Chinesa, “ultrapassando Hong Kong e Singapura” e já previam "um crescimento anual de 9\% ao ano para atingir, em 2011, um PIB de 519 bilhões de dólares (dois trilhões de Yuan)" (Pinheiro-Machado, 2009: 68). A região concentra pequenas, médias e grandes indústrias e produz desde pequenas e baratas mercadorias até as mais altas tecnologias, indústria química, petroquímica, automobilística e de produção de navios.

Aquelas previsões foram confirmadas, pois dados estatísticos posteriores acusaram crescimento de 9,2\% do Produto Interno Bruto da China, em 2011. O PIB chinês terminou naquele ano em 47,15 trilhões de yuan, ou cerca de US\$7,46 trilhões, segundo artigo publicado no jornal “O Globo" em janeiro de 2012. “Mesmo com a pequena desaceleração em 2011, a China ainda deve registrar a maior taxa de crescimento entre os países relevantes no ano de 2012". (O Globo, 2012). No entanto, dados mais recentes mostraram que a partir de então, a economia chinesa apresentou queda em seu crescimento 9 . Em 2013, foi de 7,5\% (Folha de São Paulo, 2013).

\footnotetext{
${ }^{9}$ Em abril de 2013, a revista Exame informou que nos últimos meses, o crescimento da receita fiscal da China teria diminuído, à medida que as despesas subiram para sustentar o crescimento econômico. Ressaltou que "o déficit da China ainda está dentro de níveis administráveis, e muitos economistas tem sugerido que o país pode tolerar um déficit orçamental superior, enquanto a China tenta reequilibrar sua economia e acelerar os gastos de bem-estar social" (exame.com, 2013).
}

Brasiliana - Journal for Brazilian Studies. Vol. 2, n.2 (Nov 2013). ISSN 2245-4373. 
Segundo Rosana Pinheiro-Machado (2009), Dongguan, Shenzhen e Zhuhai fazem parte do "Grande Delta", que é o conjunto de cidades e ZEE conectadas às regiões autônomas (Macau, Hong Kong). O "Grande Delta" concentra 1/3 de toda a indústria da China e se destaca nos produtos que, um dia, foram considerados "tipicamente" "made in China": eletrônicos, relógios, brinquedos, acessórios do vestuário e plástico. Shenzhen também se caracteriza na produção de alta tecnologia. Neste universo estão aproximadamente 100 mil fábricas, além das inúmeras fabriquetas não registradas. Centenas de shoppings e atacados também fazem parte desse mundo de mercadorias, onde há presença de investidores estrangeiros, bem como muitos chineses. Milhares de pessoas "saíram das mais distintas regiões do país e dirigiram-se às ZEE em busca de trabalho na extensa zona fabril ao longo do Delta" (Pinheiro-Machado, 2009: 86). Desse modo, há uma melhoria nas condições de parte das populações migrantes e rurais, que, segundo a autora, caminham da miséria para a classe média. Contudo,

“(...) chamam atenção as frágeis condições trabalhistas a que milhões de trabalhadores ainda estão submetidos, muitas vezes em situação de risco, exploração e desamparo social. Estes migrantes trabalham em fábricas conhecidas como sweatshops ${ }^{10}$ - expressão irônica que se refere ao suor de uma jornada de trabalho exaustiva e mal-remunerada - onde o limite entre o trabalho e a miséria absoluta é extremamente tênue, o que provoca um estado constante de ansiedade, medo e sujeição" (Pinheiro-Machado, 2009: 86).

\footnotetext{
${ }^{10}$ Sweatshops, ou "lojas de suor" é o nome dado ao sistema utilizado por empresas envolvidas com a exploração extrema dos trabalhadores, caracterizado por salários abaixo do mínimo necessário à sobrevivência, ausência de quaisquer formas de garantia ou proteção trabalhista, exploração de crianças, condições de trabalho perigosas para a saúde ou ameaças, moléstias sexuais e abusos físicos e psicológicos. As jornadas de trabalho são muito maiores do que a lei determina em países desenvolvidos ou em desenvolvimento. Elas são tão longas que lembram os primórdios da Revolução Industrial na Inglaterra (Pinheiro-Machado, 2009).
}

Brasiliana - Journal for Brazilian Studies. Vol. 2, n.2 (Nov 2013). ISSN 2245-4373. 
Isto ocorreu devido às reestruturações industriais e acabou por afetar milhões de pessoas, uma "população flutuante", um contingente que serve de mão de obra à indústria. São pessoas que não recebem proteção trabalhista pelo fato de não se encontrarem registradas na cidade onde trabalham, por conseguinte, sem direitos à educação, saúde e aposentadoria. No dizer de Pinheiro-Machado:

“Um dos temas mais discutidos atualmente no âmbito da Antropologia /Sociologia da China é o estado das "populações flutuantes" (lindong renkou), que são trabalhadores migrantes oriundos das zonas rurais e a mão-de-obra capaz de sustentar o crescimento (...) o sistema nacional de Registro Doméstico (hukou) é um fator crucial no entendimento das "populações flutuantes". Trata-se de um registro que fixa as pessoas em uma determinada localidade, limitando a liberdade de movimento no país e, consequentemente, os seus direitos sociais." (Pinheiro-Machado, 2009: 88-89)

Reafirmando o que indicam os estudos de Pinheiro-Machado (2009), Douglas de Toledo Piza (2012) ressalta que a nova distribuição dos espaços e o redirecionamento dos fluxos populacionais após as reformas na China seguem a lógica da economia de mercado, imposta por parte do Estado para que os migrantes internos viessem a se tornar trabalhadores nas fábricas das regiões industrializadas. Ao mesmo tempo, passou a ser garantido o reconhecimento de cidadania aos ultramarinos, com a finalidade de atrair investimentos externos para a indústria. Se o emprego formal permite atualmente a migração autorizada, a "população flutuante" em torno das cidades industriais não deixa de movimentar as fábricas através do trabalho informal, sujeitando-se a condições 
de trabalho árduas, de exploração e desamparo social. Segundo os autores, a "população flutuante" compõe a maioria da força de trabalho nessas cidades, um exército de reposição de mão de obra que não para de chegar e cuja "aposentadoria" pode tanto significar a mendicância de mutilados nas ruas como as histórias de mobilidade social e enriquecimento.

Enquanto o Delta do Rio Pérola, na província de Guangdong, atrai enorme contingente de migrantes "flutuantes", parte dos cantoneses decide pela diáspora comercial (Pinheiro-Machado, 2009 e Piza, 2012). Faz-se necessário, portanto, compreender todo o processo que teria propiciado essa diáspora, agora "comercial", que promove a abertura de centros atacadistas abastecedores do comércio varejista de chineses, locais e de outros migrantes. Estudos sobre a China apontam que a informalidade e a mobilidade são características dessa modalidade de diáspora (Pinheiro-Machado, 2009 e Piza, 2012). Entretanto, ainda não temos dados que nos possibilitem concluir uma maior ou menor relação daquelas características com a existência de trabalho escravo.

\section{O Caminho Exploratório}

A pesquisa tem buscado conhecer quem são esses migrantes trabalhadores chineses, onde e como podem ser encontrados, quais são as relações travadas entre eles e seus patrões e o que as mantém. $\mathrm{O}$ aspecto político-econômico não pode ser obscurecido nessa busca, conforme alerta Claude Meillassoux (1995) ao se referir à escravidão como um sistema social. ${ }^{11}$

\footnotetext{
${ }^{11}$ Ressalta o autor sobre a importância da análise da categoria "escravidão" a partir de uma abordagem que abarque relações de classe, não reduzindo esta abordagem à relação individualizada entre escravo e senhor. Pois seria a partir da perda dos vínculos de nacionalidade ou de parentesco, da ausência das relações humanas tradicionais na retirada de seu meio social que se afirmaria naquele indivíduo o estado de escravo. (Meillassoux, 1995)
}

Brasiliana - Journal for Brazilian Studies. Vol. 2, n.2 (Nov 2013). ISSN 2245-4373. 
No início do percurso exploratório a equipe aproximou-se de três voluntários que se dedicam ao tema da migração chinesa pela via da religiosidade. Através desse contato foi possível conhecer um grupo de chineses inseridos no universo cristão evangélico, no Rio de Janeiro. Encontros acontecem aos domingos, após cerimônia religiosa, momento em que os mesmos se reúnem com parte da equipe. Esses contatos são realizados em uma igreja que fica localizada em um bairro localizado na zona norte do Rio de Janeiro. Em apresentação do que foi feito até então, tivemos conhecimento de relatos que podem nos trazer subsídios para reflexões, sobretudo em relação à cultura dos chineses.

Buscamos entender como se deu a chegada daqueles chineses no Brasil, porque migraram e de que forma. Há relatos que traduzem a vinda de apenas parte de famílias, que fica na espera dos outros membros. Em alguns casos, o casal vem primeiro com os filhos e, posteriormente, chegam os avós. Em outros, os filhos adultos vêm para o Brasil e aguardam os pais, que chegam depois. Pode acontecer de primos, irmãos e irmãs rumarem ao Brasil e ficarem à espera de pais, tios que viriam em outro momento. São acordos feitos anteriormente com intenção de reconstruírem suas vidas, especialmente no trabalho ligado ao comércio. Foi observada a chegada de jovens, inclusive mulheres para iniciar a vida laboral no Brasil. Houve um caso em que um casal, com dois filhos, veio da Itália para visitar a irmã de um dos cônjujes e, ao verificar a necessidade de ajuda a esta irmã, resolveu também ficar.

A entrevista de uma jovem chinesa em uma das igrejas apontou que a mesma está no Brasil há aproximadamente 15 anos, mora em um dos bairros da cidade com a mãe e o irmão, estuda e trabalha na área de importação. Seus pais vieram antes, primeiro a mãe, depois o pai. Ela havia ficado na China com os avós. Segundo seu relato, hoje em dia os chineses agem da seguinte forma: “a gente tem filho aqui (...), após ser criada por cinco/seis meses com nacionalidade brasileira, volta para a China, estuda 
até os seis/sete anos e vem para cá de novo. Com isso, a criança aprende o mandarim perfeitamente e o português também". Afirmou que seus pais vieram para o Brasil abrir um comércio, pois a situação sócio-econômica estava bastante conturbada na China até o final dos anos noventa. Ressaltou sobre a dificuldade de adaptação por parte de seus pais ao chegarem ao Brasil, principalmente por não conhecerem a língua portuguesa. E esclareceu:

"Na linguagem do dia a dia ele consegue comprar alguma coisa, passear, viajar, mas pegar um contrato para ler, ele não consegue. Tem dificuldades formais, entendeu? E aí eles acabam colocando essa responsabilidade para cima dos filhos. Então, desde criança você já começa a ler contrato, liga para o médico para cancelar alguma consulta, sabe? Coisas simples, mas que acabam tornando-se difíceis. Se você ligar para uma loja chinesa, por exemplo, o cara é o dono, mas ele passa pro filho que tem dez anos."

A observação feita por parte da equipe nas visitas a esse grupo religioso tem mostrado, em suas narrativas, que não se trata de pessoas que vieram em busca de emprego, mas de negócios, talvez de transações comerciais de forma autônoma, abertura de estabelecimentos ou sociedades com os que aqui já se encontravam. Foi-nos dito que a idéia transmitida é de que "servir" ao outro, isto é, ser empregado, não é encarado como algo positivo. Muitos deles deixam claro que preferem estar na situação de dirigentes, empregadores, em níveis hierárquicos superiores. A entrevistada afirmou que o principal motivo que leva à imigração chinesa ao Brasil é o aspecto econômico, que as pessoas vêm pelas oportunidades, "só vêm pela questão do dinheiro". O grupo de 
chineses frequentadores dessa instituição religiosa está aparentemente vinculado a negócios, são empregadores em sua maioria, ou familiares desses empregadores.

Diferentemente desse perfil de migrantes chineses foi encontrado outro grupo em visita à igreja localizada em um município da baixada fluminense. Tudo indica que esses chineses fazem parte de uma classe menos privilegiada economicamente, que teriam vindo em busca de emprego, sem disponibilidade para abrir algum tipo de negócios.

Nos meses de janeiro e agosto de 2013 realizamos entrevistas com um historiador e doutor Shu Chang-Sheng, chinês, 45 anos, quem trouxe contribuições relevantes à pesquisa ora iniciada. Veio para o Brasil em 1995, na condição de estudante de intercâmbio. Cursou o Mestrado na área de Economia da Universidade Federal Fluminense - UFF. Em seguida, no ano de 2002, realizou seu doutorado na área de Historia, também na UFF.

Segundo ele, a maioria dos chineses que migram para o Brasil vem de Cantão, província de Guangdong. Muitos vêm sozinhos, mas logo depois trazem as famílias. Ou há muitos casos de jovens vindos através de organizações clandestinas que migram especialmente por falta de emprego no país de origem, para poder ter uma vida melhor e enviar dinheiro às famílias que moram na China. Isso não exclui a existência de casos em que demandas pessoais venham a favorecer essas migrações.

No entanto, com as mudanças ocorridas na China nas três últimas décadas, com a simplificação dos processos de liberação e emissão de passaportes e o crescimento das agências de migração nas grandes cidades (Hong Kong, Xangai, Macau), mais imigrantes entraram no Brasil de forma legal através de agenciadoras. Estas não são empresas registradas, trata-se de pessoas que lucram com isso, por exemplo, um agenciador de Hong Kong, um representante dos Estados Unidos com acesso a um canal de migração 
ou que conheça alguém no Brasil, talvez até do governo. Haveria na China os agenciadores; no Brasil, os mediadores.

O pesquisador concluiu terem sido os chineses os "primeiros imigrantes estrangeiros que chegaram ao Brasil no século XIX para trabalhar na agricultura", por meio do tráfico dos coolies ${ }^{12}$. Em seu artigo relatou a história de chineses no Brasil:

“Uma colônia de chineses foi trazida de Macau para o Rio de Janeiro pelo Governo Real Português, entre 1812 e 1819, de maneira a introduzir a cultura do chá no Brasil. Tratava-se de um projeto econômico estratégico, organizado pelo governo de Dom João VI, estimulado pelo Ministro do Reino, Conde de Linhares - nesse período, o posto era representado por Francisco de Sousa Coutinho Teixeira de Andrade Barbosa (1790-1857), - e protegido pelo Ministro de Guerra e dos Estrangeiros, Conde de Barca - Antonio de Araujo e Azevedo (17541817). O plano foi instituído em 1810 e, dois anos depois, chegaram ao Rio cerca de 300 chineses, além de mudas e sementes de chá vindas de Macau no navio Vulcano. (...) o cultivo de chá pelos chineses foi, de modo geral, considerado um fracasso. (...) os próprios chineses não aceitavam de forma passiva as condições de servidão dentro da fazenda imperial" (Chang-Sheng, 2009: 45-46).

\footnotetext{
${ }^{12}$ Como eram chamados os "trabalhadores livres, geralmente chineses ou indianos, que se espalhavam pelo mundo principalmente pelos territórios coloniais europeus - em troca de salários muito abaixo dos comumente praticados, e que haviam sido fundamentais como mão-de-obra alternativa no contexto de abolição da escravidão nas colônias britânicas, na primeira metade do século XIX. Na América Latina, os coolies atuavam desde pelo menos os anos 1860 em países como o Peru e Cuba. Nos Estados Unidos na segunda metade oitocentos, foram empregados especialmente na construção ferroviária e na exploração do ouro na Costa Oeste, apesar do Chinese Exclusion Act de 1882 ter banido legalmente esta forma de imigração" (Yang, 1977: 419).
}

Brasiliana - Journal for Brazilian Studies. Vol. 2, n.2 (Nov 2013). ISSN 2245-4373. 
Esclareceu que em 1881, Brasil e China assinaram um tratado proibindo a contratação de mão de obra coolies. Porém, apesar da proibição, atividades ilegais do contrabando de coolies receberam apoio do governo brasileiro. Além disso, estava tornando-se antieconômico a sua compra. Assim, começou a haver uma substituição de escravos negros pela mão de obra chinesa. Os chineses, então, começaram a trabalhar em construção de estradas, ferrovias em São João Del Rei (Minas Gerais) e no Rio de Janeiro. Eram trazidos para o Brasil de navio em condições subhumanas. Havia um contrato de trabalho que se referia às dívidas, além da proibição de saída do local de trabalho e da inexistência de liberdade de expressão. Informou-nos ainda que, com a abolição da escravatura em 1888, encerrou-se essa prática como sistema político. A migração passaria a ser "voluntária".

Apesar do que foi posto pelo historiador chinês, caberia uma reflexão com relação à persistência da escravidão por dívida entre os chineses, no contexto atual. Ocorrem, a partir da informalidade, de relações ilegais entre imigrantes e há indícios de que haja utilização de mão de obra escrava de migrantes chineses no Brasil. Como já foi dito, muitos chegam ao Brasil para trabalhar em restaurantes, pastelarias ou comércio de artigos de seu país natal, financiados por agenciadores. Muitos destes agenciadores, segundo Chang-Sheng, são ingleses estabelecidos em Hong Kong. Ao buscarem uma vida melhor, através de um emprego no Brasil, os migrantes recorrem a eles para viabilizar o processo de sua saída da China e a entrada no Brasil, contraindo uma dívida. Como pretendem viajar, acabam por tomar empréstimos com a própria família ou com amigos para pagar àquele agenciador. Ao chegarem ao Brasil têm que trabalhar exaustivamente, às vezes 14 horas por dia, para honrar a dívida contraída. A escravidão, portanto, parece ressurgir com outra roupagem.

Uma pesquisa realizada com migrantes em região do Rio de Janeiro revelou que um importante fator no sucesso dos empreendedores chineses reside em suas relações 
específicas de trabalho. Há dedicação completa e total por parte dos empregados “muitas vezes impulsionada por dívidas financeiras ou de gratidão. Muitos chegam até mesmo a considerar essas relações como forma de trabalho escravo" (Cunha \& Mello, 2003:162-163). No Estado de São Paulo, outro estudo (Piza, 2012) confirmou que há “elementos dúbios de solidariedade e exploração, ajuda e aprisionamento" nas relações existentes entre migrantes chineses que atuam na região da Rua 25 de março, na cidade de São Paulo.

Não perdendo de vista a complexidade das questões determinantes do sucesso financeiro de chineses em outros países, Eduardo Figueiredo Siebra (2010) sinalizou para a relevância que podem assumir os valores culturais asiáticos na vida profissional. Embora com limites democráticos, a ética confuciana, produto de ideologia presente na sociedade chinesa, traz um enfoque comunitário ao valorizar o trabalho árduo, a disciplina, a educação e o sacrifício pessoal. Tradicionalmente, uma ênfase foi dada pelos chineses aos deveres em detrimento dos direitos individuais, ao desenvolvimento coletivo em lugar da realização pessoal (Siebra, 2010). Os encontros realizados semanalmente pela equipe com frequentadores de uma igreja evangélica chinesa no Rio de Janeiro confirmaram a "naturalização", por parte dos mesmos, dessa forma de trabalho exaustivo.

Por outro lado, a partir das mudanças ocorridas na economia e na organização política e social da China passou a haver um incentivo ao empreendedorismo e ao consumo por parte do Estado, o que muitas vezes se traduz em interesses e valores individualistas, mesmo em meio a relações de grupos e redes. Esse aspecto tem sido utilizado como argumento em críticas referentes a estudos que enaltecem o coletivismo de caráter étnico: “Os negócios em família, enfim, não constituem uma persistência da tradição, mas uma reinvenção da mesma dentro das demandas de um contexto global" (Pinheiro-Machado, 2009: 169). 
Outra entrevista realizada com o presidente do SAARA (Sociedade de Amigos das Adjacências da Rua da Alfândega) corroborou para esclarecer-nos sobre o porquê da vinda de grande massa de chineses ao Brasil a partir da década de 1990. Muitos buscam meios de sobrevivência, emprego e melhores condições de vida, tendo em vista a situação precária em que se encontravam na China. Por outro lado, comerciantes chineses chegam com dinheiro suficiente para adquirirem um estabelecimento comercial e iniciarem seus negócios. Uns e outros estabelecem entre si relações. Estamos interessados em conhecer como se dão essas relações em suas especificidades.

Embora ainda não haja estatística quanto à existência de migrantes no Brasil vivenciando situações de escravidão por dívida, a categoria pode aparecer nas relações travadas entre patrão e empregados, nas condições degradantes e no trabalho exaustivo presentes em pastelarias e ou em outros estabelecimentos comerciais chineses.

Houve um caso concreto de escravidão por dívida, em que foi possível o acomanhamento pela equipe. É este caso que descreveremos nas próximas linhas.

\section{Aspectos da Trajetória dos Migrantes Chineses no Brasil: O Caso Yan}

O jovem chinês Yin, de 23 anos, veio ao Brasil com intenção de trabalhar, encontrar meios de sobrevivência e melhores condições de vida, tendo em vista a precária situação em que se encontrava na província de Guangdong, na China, onde trabalhava em fábrica têxtil e ajudava sua mãe no campo. Como ele, muitos outros chineses chegaram ao Brasil, especialmente a partir da década de 1990, com o mesmo objetivo.

Yin saiu de sua cidade no mês de maio de 2012, após ter sido convidado a trabalhar em uma pastelaria, na cidade do Rio de Janeiro, pelo próprio dono. Ao chegar ao Brasil, percebeu ter sido vítima de promessas de salário não cumpridas e a ser privado de sua liberdade, além de sofrer violências morais e físicas. Por não possuir 
meios de se comunicar, já que não conhecia outro idioma além do mandarim e do dialeto cantonês, ficava impossibilitado de pedir ajuda.

O caso Yin tornou-se público após uma denúncia anônima, em 02 de abril de 2013, que decorreu de situações de espancamento e gritos que aconteciam dentro de uma pastelaria localizada no bairro de Parada de Lucas, no Município do Rio de Janeiro. Yin foi resgatado pela Polícia Civil, da 38a․ Delegacia de Polícia da Secretaria de Estado de Segurança - SESEG, no bairro de Vista Alegre, no Rio de Janeiro, com múltiplas e graves lesões, além de edemas pelo corpo todo. Estava muito machucado, com fortes dores e o rosto parcialmente transfigurado, principalmente com suspeição de fratura da mandíbula.

O auto de apreensão da referida Delegacia de Polícia confirmou a presença de alguns crimes contra Yin cometidos por seu patrâo Yan Ruilong, também chinês, 26 anos. Com base no Código Penal Brasileiro foi acusado de: redução de Yin à condição análoga à de Escravo (art. 149); frustração de Direito assegurado por lei trabalhista (art. 203); omissão de socorro (art. 135), além de crimes de espancamento e tortura segundo a lei 9.455/97. Foi levantada a hipótese de o ofendido ter sido vítima da máfia envolvida com o tráfico de pessoas. No terceiro artigo do decreto 5.017 de 12 de março de 2004, conhecido como "Protocolo de Palermo", a expressão "tráfico de pessoas" encontra-se definida como:

“(...) o recrutamento, o transporte, a transferência, o alojamento ou o acolhimento de pessoas, recorrendo à ameaça ou uso da força ou a outras formas de coação, ao rapto, à fraude, ao engano, ao abuso de autoridade ou à situação de vulnerabilidade ou à entrega ou aceitação de pagamentos ou benefícios para obter o consentimento de uma pessoa que tenha autoridade sobre outra para fins de exploração. A exploração 
incluirá, no mínimo, a exploração da prostituição de outrem ou outras formas de exploração sexual, o trabalho ou serviços forçados, escravatura ou práticas similares à escravatura, a servidão ou a remoção de órgãos; b) $\mathrm{O}$ consentimento dado pela vítima de tráfico de pessoas tendo em vista qualquer tipo de exploração descrito na alínea a) do presente Artigo será considerado irrelevante se tiver sido utilizado qualquer um dos meios referidos na alínea a); c) $\mathrm{O}$ recrutamento, o transporte, a transferência, o alojamento ou o acolhimento de uma criança para fins de exploração serão considerados "tráfico de pessoas" mesmo que não envolvam nenhum dos meios referidos da alínea a) do presente Artigo; d) O termo "criança" significa qualquer pessoa com idade inferior a dezoito anos" (Brasil. Decreto n. 5017 de 12/03/2004).

Consta no auto da Polícia Civil a determinação de que se oficiasse tanto a Polícia Federal quanto ao Ministério Público do Trabalho. Paralelamente aos referidos procedimentos, a Polícia Federal foi também acionada pelo Ministério do Trabalho e Emprego, após ter sido alertado pela Comissão Estadual de Erradicação do Trabalho Escravo - COETRAE do estado do Rio de Janeiro, para a necessidade de investigação do caso pela possibilidade de se tratar de trabalho escravo. A COETRAE havia tomado conhecimento do caso através da mídia, o que possibilitou essa interlocução.

Da Delegacia, Yin foi encaminhado ao Hospital Estadual Getúlio Vargas, no bairro da Penha, cidade do Rio de Janeiro. Ao chegar ao hospital, foi diretamente para a Unidade de Terapia Intensiva - UTI, onde permaneceu por vários dias. Após pequena melhora, embora amedrontado, Yin aceitou prestar seu depoimento à Polícia Civil que o havia resgatado, na presença de alguns policiais da Polícia Federal, de membros do Ministério do Trabalho e Emprego, do Ministério Público do Trabalho e do GPTEC. 
Como Yin não falava o idioma português e as autoridades não falavam o mandarim, uma pessoa indicada pelo Consulado chinês fez a primeira tradução do mandarim para o português, sem que surgisse algum dado relevante além do já demonstrado nos ferimentos do trabalhador. Em conversa informal, esse suposto tradutor revelou ter dois estabelecimentos comerciais e participar da Associação Cultural Chinesa. Diante de tais informações e, levando em conta sua atitude no momento da tradução, parecia que o intérprete tentava induzir o entrevistado a não denunciar o ex-patrão, utilizando inclusive o dialeto cantonês, confundindo os presentes em alguns momentos. Quando a pergunta sobre processar ou não o patrão era feita a Yin, o intérprete tentava induzi-lo a não fazer a acusação. A equipe supõe um possível envolvimento do mesmo em atos ilícitos. Tratar-se-ia de partícipe em relações mafiosas?

O próprio Yin relatou em outra entrevista que não havia se sentido confortável próximo àquele intérprete, que tinha conhecimento da relação do mesmo com o dono da pastelaria. Yin, então, pôde expor o problema enfrentado desde sua chegada ao Brasil a outro intérprete, participante voluntário da pesquisa. Este intérprete fala o cantonês e o mandarim com muita desenvoltura, motivo que fez com que, a partir daí, as declarações de Yin alcançassem maior fidedignidade. Com essa mediação completava-se o trabalho de tradução mandarim-inglês-português, proporcionando aos presentes maior entendimento do problema, bem como da rota de saída da China. Apesar dos percalços e dificuldades na tradução e do número elevado de pessoas no local, ficou claro tratar-se de um caso de escravidão por dívida, de impedimento à liberdade, de tortura e reclusão.

O trabalho escravo no Brasil é considerado por organizações sociais e servidores públicos como a submissão do trabalhador através de alguma forma de pressão física ou psicológica. No Ocidente, o mecanismo mais comum para justificá-lo é a dívida. Contudo, pela atual legislação, também é considerado trabalho escravo o 
trabalho degradante ou exaustivo. Todos estes aspectos são encontrados na relação entre Yin e seu patrão.

Nos relatos de Yin foram revelados aspectos que corroboram e justificam tratar-se de caso de escravidão. O jovem chinês informou que sofria ameaças por parte do patrão por ser mais lento que os outros funcionários, que o mesmo o mataria se não trabalhasse de forma mais rápida. $\mathrm{O}$ entrevistado revelou que seu patrão usava correntes para agredi-lo e que muitas vezes o queimava com cigarros. Narrou também que, como existiam câmeras na pastelaria, o dono do estabelecimento o ameaçava e dizia que estaria constantemente sendo monitorado em seu trabalho. Só lhe era permitido sair na companhia do patrão quando este assim o desejava.

Ao ser indagado sobre o fato de não pedir socorro, narrou que algumas vezes chegou a fazê-lo através de gestos para os clientes da pastelaria, mas que não obteve sucesso. Em situação ilegal no país, sem dinheiro, sem falar a língua local, sem uma rede de proteção tornava-se quase impossível vislumbrar uma fuga.

Durante a conversa, Yin afirmou que, ao ser convidado para trabalhar no Brasil, foi-lhe solicitado que viajasse com poucas roupas e lhe informado que ficaria hospedado em um hotel, na China por dois dias, quando, então, embarcaria para o Brasil. Nos dois dias em que permaneceu no hotel recebeu treinamento cujas instruções incluíam formas de como se comportar na aeronave e de oferecer respostas às perguntas da imigração, tais como dizer que estava em trânsito e que não pretendia se fixar no país, já que o Brasil não seria o seu destino final.

Dentre as promessas que recebeu na China, Yin informou que lhe ofereceram um salário mensal de $\mathrm{R} \$ 1.500,00$ (mil e quinhentos reais). Vale ressaltar a importância desse valor dada à discrepância entre os cem dólares que recebia em Guangdong. Na realidade, do montante prometido, a maior parte seria utilizada para pagar a dívida com despesas de sua viagem, no valor de $\mathrm{R} \$ 30.000$ (trinta mil reais). Dessa forma, ao começar a 
trabalhar na pastelaria com o Sr. Yan Ruilong, conhecido da vizinha de sua mãe, em Guangdong, receberia apenas o valor mensal de $\mathrm{R} \$ 200,00$ (duzentos reais), sem mais despesas, já que alimentação e moradia seriam no próprio local de trabalho. Ao final de três anos, prazo do contrato informal estabelecido entre empregado e patrão, caso Yin quisesse continuar no Brasil, passaria a receber o valor prometido inicialmente.

Diante do exposto e do fato de que a dívida de Yin não tenha sido contraída com amigos ou familiares, mas com o próprio empregador, tornou-se claro a vinculação desta com o trabalho e, portanto, a presença da escravidão por dívida.

Por parte da Polícia Civil, houve cooperação com as outras instituições durante o processo. No entanto, desconsiderando o constante no Protocolo de Palermo, a Polícia Federal teria pretendido deportar o jovem chinês para que ficasse encerrado o caso. Há que se ressaltar para a importância da conjugação das instâncias criminal e trabalhistas no alcance dos objetivos relacionados aos direitos humanos no que concerne à pessoa de Yin. Provavelmente, sem a atuação das instituições trabalhistas o caso se encerraria com a deportação do jovem chinês. O Protocolo de Palermo deixa claro que o Estado deve proteger e não perseguir o traficado. Na letra b do segundo artigo, o Protocolo explicita a "assistência para permitir que as suas opiniões e preocupações sejam apresentadas e tomadas em conta em fases adequadas do processo penal instaurado contra os autores das infrações, sem prejuízo dos direitos da defesa". E no artigo número 6 consta que “cada Estado Parte assegurará que o seu sistema jurídico contenha medidas que ofereçam às vítimas de tráfico de pessoas a possibilidade de obterem indenização pelos danos sofridos (Brasil. Decreto n. 5017 de 12/03/2004).

Em setembro de 2013, Yin encontrava-se, ainda, sob a proteção do governo brasileiro. Seu ex-patrão, dono da pastelaria, "foi preso e autuado pelos crimes de tortura, redução à condição análoga à de escravidão e omissão de socorro" (Jornal O Dia, 2013: 17).

Brasiliana - Journal for Brazilian Studies. Vol. 2, n.2 (Nov 2013). ISSN 2245-4373. 


\section{Considerações Finais}

Diante do ocorrido com Yin, levantamos a hipótese de que este caso pode ser a ponta de um problema que sinaliza um número elevado de chineses em condição de trabalho escravo ou vítimas do tráfico de pessoas.

Muitas pessoas podem estar passando pela mesma situação, pois as questões que envolvem o caso podem atingir outros tantos migrantes chineses no Brasil, dos quais ainda não temos conhecimento, especialmente daqueles que estão no país de forma ilegal.

Foi observado no decorrer do caminho exploratório que há diferenças quanto a níveis sociais, educacionais, religiosos entre os migrantes chineses. Por outro lado, observou-se que, apesar das diferenças, mantém-se o forte entrelaçamento entre pessoas de uma mesma família ou entre grupos. Porém, esse estreitamento de relações ressaltado por autores estudiosos da migração chinesa vem apresentando mudanças em vários aspectos. Confirmou-se que as redes estabelecidas entre os chineses apontam a marca dessa etnia. Porém, conforme estudos já abordados, as relações em rede não estão pautadas apenas em solidariedade ou cooperativismo, neutras de interesses. Podem estas ser entendidas como relações necessárias ao atendimento de demandas globais e pessoais.

Não há intenção de se negar a importância das condições objetivas inerentes ao contexto político e econômico presentes na China. São processos sociais amplos que incluem trabalho intensivo, reestruturações sócio-políticas, adesão à economia de mercado com características específicas. No entanto, a pesquisa tem sinalizado a forma de relacionamentos pautados em redes como outro fator relevante para o entendimento 
do avanço alcançado por muitos chineses nos negócios e das modalidades de trabalho das quais os mesmos se utilizam.

Há que se destacar um aspecto primordial a ser analisado no que diz respeito a críticas atribuídas aos modos de pertencimento às redes nos diferentes contextos. $\mathrm{O}$ êxito econômico aparece, na maioria das vezes, vinculado a um grupo de proprietários, enquanto há grande parte de migrantes mal sucedidos e sujeitados a relações desfavoráveis. São relações que, em alguns casos, podem alcançar o limite da subordinação ou ainda levar à aparente ausência de resistência.

\section{Referências Bibliográficas}

Brasil. Presidência Da República. Decreto № 5.017, de 12 de Março de 2004. Diário Oficial da União, Brasília, DF, ano 2004, n.50, 15 março 2004. Seção 1, p. 10.

"Bovespa sobe apoiada por PIB da China e ações de Eike; dólar cede". In: Folha de São Paulo. São Paulo, 15 julho 2013, Mercado. Disponível em: < http://www1.folha.uol.com.br/mercado/2013/07/1311282-bovespa-sobe-apoiada-por-pibda-china-e-acoes-de-eike-dolar-cede.shtml> Acesso em 22 ago 2013.

Chang-Sheng, Shu. "Chineses no Rio de Janeiro". In: Leituras da História Ciência e Vida. Rio de Janeiro, ano II, n. 17, 2009, p. 44-53.

Chang-Sheng, Shu. A História da China Popular no século XX. Rio de Janeiro: FGV Editora, 2012.

Chauí, Marilena. Convite à Filosofia. São Paulo: Ed Ática, 2000, pp. 374-376.

"China espera manter déficit fiscal abaixo de 3\% do PIB". In: Exame.com, 29 julho 2013, Economia. Disponível em: < http://exame.abril.com.br/economia/noticias/china-esperamanter-deficit-fiscal-abaixo-de-3-do-pib> Acesso em 22 ago 2013.

Cunha, Neiva Vieira da e Mello, Pedro Paulo Thiago de. Libaneses e Chineses: sucessão, conflito e disputa numa rua de comércio do Rio de Janeiro. In: Anuário Antropológico /2005. Rio de Janeiro: Tempo Brasileiro, 2006. p. 55-169. 
Cunha, Vania, Valdevino, Diego. Monstruosidade na pastelaria. In: O Dia, 04 abr, 2013, p.17.

Elias, Norbert e Scotson, John L. Os estabelecidos e os outsiders: Sociologia das relações de poder a partir de uma pequena comunidade. Rio de Janeiro: Jorge Zahar Ed, 2000.

Haidar, Daniel. "PIB da China faz "pouso suave" com alta de 9,2\% em 2011". In: $O$ Globo, Rio de Janeiro, 17 janeiro 2012, Economia. Disponível em: < http://oglobo.globo.com/economia/pib-da-china-faz-pouso-suave-com-alta-de-92-em2011-3690092> Acesso em 22 ago 2013.

Meillassoux, Claude. Antropologia da escravidão: o ventre de ferro e dinheiro. Rio de Janeiro:Jorge Zahar Ed, 1995.

Pinheiro-Machado, Rosana. Made in China: produção e circulação de mercadorias no circuito China-Paraguai-Brasil. Tese de doutorado, Universidade Federal do Rio Grande do Sul, Porto Alegre, 2009, $332 \mathrm{f}$.

Piza, Douglas de Toledo. Um pouco da mundialização contada a partir da região da Rua 25 de março: migrantes chineses e comércio informal. Dissertação de Mestrado, Universidade de São Paulo, São Paulo, 2012, 196 f.

Siebra, Eduardo Figueiredo. Cultura e Direitos Humanos na China Contemporânea: uma investigação metodológica. Dissertação de mestrado, Universidade Federal de Pernambuco, Recife, 2010, $247 \mathrm{f}$.

Universidade Federal de Campina Grande. Só Biografias. Textos compilados e digitados pelo Prof. Carlos Fernandes. Disponível em: < http://www.dec.ufcg.edu.br/biografias/> Acesso em: 10 set 2013.

Yang, Alexander. "O Comércio dos 'Coolie' (1819-1920)”. In: Revista de História, v. LVI, n. $112,1977$. 